\title{
ß-hydroxy-ß-methylbutyrate (HMB) attenuates muscle and body weight loss in experimental cancer cachexia
}

\author{
ZAIRA AVERSA ${ }^{1 *}$, ANDREA BONETTO ${ }^{2 *}$, PAOLA COSTELLI ${ }^{2}$, VALERIO GIACOMO MINERO $^{2}$, \\ FABIO PENNA ${ }^{2}$, FRANCESCO MARIA BACCINO ${ }^{2}$, SIMONE LUCIA ${ }^{1}$, \\ FILIPPO ROSSI FANELLI $^{1}$ and MAURIZIO MUSCARITOLI ${ }^{1}$ \\ ${ }^{1}$ Department of Clinical Medicine, Sapienza University of Rome; \\ ${ }^{2}$ Department of Experimental Medicine and Oncology, University of Turin, Italy
}

Received August 31,2010; Accepted October 7, 2010

DOI: $10.3892 /$ ijo.2010.885

\begin{abstract}
HMB), a leucine metabolite, improves muscle mass and function. This study aimed at evaluating the effects of HMB administration in an experimental in vivo model of cancer cachexia (CC). Wistar rats were randomized to receive standard or $4 \% \mathrm{HMB}-$ enriched chow. Rats from both groups were randomized to receive an i.p. inoculum of AH-130 cells (TB). All rats were weighed and sacrificed at day 24. Liver, heart and muscles were dissected and weighed. The protein levels of p-p70S6k, p-eIf $2 \alpha$, -mTOR and p-4-EB-P1 were evaluated by Western blotting on gastrocnemius muscle (GSN). As expected, the growth of the AH-130 ascites hepatoma induced significant carcass weight and GSN muscle loss. HMB treatment significantly increased GSN and heart weight in controls $(\mathrm{p}=0.002$ and $\mathrm{p}<0.001$, respectively). In HMB-treated TB, body weight was not lost but significantly $(\mathrm{p}=0.003)$ increased, and GSN loss was significantly $(\mathrm{p}=0.04)$ attenuated with respect to TB. Phosphorylated eIF $2 \alpha$ markedly decreased in TB-rats vs. C. Feeding the HMB-enriched diet resulted in decreased p-eIF $2 \alpha$ levels in control animals, while no changes could be observed in the TB group. Phosphorylated p70S6K and phosphorylated mTOR were markedly increased by HMB treatment in controls and further increased in TB. Phosphorylated 4-EB-P1 was markedly increased in TB but substantially unaffected by HMB treatment. Administration of HMB attenuates body weight and muscle loss in experimental CC. Increased phosphorylation of key anabolic molecules suggests that these actions are mediated by improved protein anabolism in muscle.
\end{abstract}

Correspondence to: Dr Maurizio Muscaritoli, Department of Clinical Medicine, Viale dell' Università 37, 00185 Rome, Italy

E-mail: maurizio.muscaritoli@uniroma1.it

*Contributed equally

Key words: cancer, cachexia, muscle, ß-hydroxy-ß-methylbutyrate

\section{Introduction}

Cancer cachexia is a devastating syndrome characterized by loss of body weight and muscle mass which affects patients' morbidity, mortality and quality of life (1). Muscle loss has serious clinical consequences such as decline in functional status, increased disability risk and alteration of respiratory muscle function (2).

In normal conditions, muscle mass is maintained by equal rates of protein synthesis and degradation. In catabolic conditions, this balance is shifted towards loss of muscle tissue by increased muscle protein breakdown (3). The ATPubiquitin-dependent system (4) plays a pivotal role in protein degradation in wasting conditions, although the lysosomal compartment (5), the $\mathrm{Ca}^{2}$-dependent proteolysis (6) and caspases (7) may be involved as well.

Besides the degradative pathways, however, recent data suggest that anabolic pathways might also be involved. In particular, the potential role of insulin-like growth factor-1 (IGF-1) and myostatin in the pathogenesis of cancer cachexia have gained particular attention during recent years $(8,9)$.

Despite several lines of evidence showing that body weight loss and muscle depletion are associated to a worse outcome, no effective treatment for cancer cachexia is available. Therefore, cancer cachexia remains a major plague in clinical practice in need of effective preventative or therapeutic remedies.

One potential strategy could be to use targeted nutritional supplementation aimed at stimulating the process of protein synthesis and attenuating protein breakdown.

ß-hydroxy- $\beta$-methylbutyrate (HMB) is a metabolite of the branched-chain amino acid leucine (LEU), formed by transamination to $\alpha$-ketoisocaproate in muscle followed by oxidation of the $\alpha$-ketoisocaproate in the cytosol of the liver, and possibly other tissues (10). Both LEU and $\alpha$-ketoisocaproate have been proposed to decrease nitrogen and protein loss during periods of excessive catabolism (as severe stress or trauma) (11) through the production of HMB, thought to be responsible for the inhibitory effect on protein breakdown (12).

HMB appears to exert its effect by attenuation of PIFinduced increase of the ubiquitin proteasome pathway through 
the inhibition of PKC (protein kinase-C), with resultant stabi-

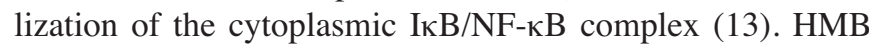
is also thought to stimulate protein syntesis (14), possibly by attenuating the inhibition of protein synthesis which occurs during cancer growth $(15,16)$. It is noteworthy that the ongoing investigation on the possible molecular mechanisms through which HMB may exert its action on muscle trophism, is concomitantly providing new insights into the better understanding that protein degradation and synthesis are not separate pathways. Indeed, cross-talk signalling between protein degradative and synthetic pathways will either favour muscle degeneration or regeneration.

Clinical studies have shown the ability of HMB to increase lean body mass and muscle strength in humans undergoing progressive resistance-exercise training (17) and to attenuate signs and symptoms of exercise-induced muscle damage in non-resistance trained healthy subjects (18). In addition, the administration of a mixture containing HMB, arginine and glutamine in advanced stage (IV) cancer patients has shown efficacy in increasing both body mass and fat-free mass with respect to controls (19), but these data were not confirmed in a recent study in stage III-IV cancer patients $(20)$. Positive results were observed in $\operatorname{AIDS}(21,22)$, but not in rheumatoid arthritis patients (23). Finally, HMB alone was shown to improve nitrogen balance in trauma patients (24), and to exert anti-inflammatory actions and to improve respiratory function in critically ill COPD patients (25). It should be noted, however, that not all clinical studies support the efficacy of HMB supplementation. Possible explanations for such conflicting results, are the variability across human participants, the variability in human behaviour (influenced by participant's social milieu, motivations, selfconfidence and current emotive status) and the inadequacy of samples (number of patients studied and bias in sampling) (26) as well as insufficient compliance and high drop-out rate (20).

Finally, based on available evidence, HMB supplementation appears to be safe and not accompanied by undesired side-effects either in animals (26) or humans (12) consuming variable dosage. Gallagher et al have shown that an 8-week HMB supplementation at different dosages have no adverse effects on hepatic enzyme function, lipid profile, renal function or on the immune system in untrained men undergoing resistance training (27).

The aim of this study is to evaluate whether the early administration of HMB alone may exert positive effects in an experimental model of cancer cachexia (AH-130 Yoshida ascites hepatoma) and to investigate if HMB interferes with anabolic pathways within the muscle.

\section{Materials and methods}

The study was performed on male Wistar rats weighing $\sim 150 \mathrm{~g}$. They were housed on a regular dark-light cycle (light from 8:00 am to 8:00 pm), with free access to food and water throughout the experimental period, and cared for in compliance with the Italian Ministry of Health Guidelines (no. 86609 EEC) and the NIH Guide for the care and use of laboratory animals (NIH, 1996). After the acclimatation period, rats were randomly divided into two groups to receive standard $(\mathrm{n}=25)$ or an industrially-prepared 4\% HMB-enriched $(n=31)$ pelleted chow (Mucedola, Settimo Milanese, Milan, Italy). After 16 days, rats from both groups were randomized to receive an i.p. inoculum of $\sim 10^{8}$ Yoshida AH-130 ascites hepatoma cells $(\mathrm{TB}, \mathrm{n}=12$ and $\mathrm{TB}+\mathrm{HMB}, \mathrm{n}=15)$. Food and water intake was measured daily by animal care personnel. All rats were weighed, and sacrificed under light ether anesthesia at day 24, eight days after tumor inoculum in the TB groups. Immediately before death, blood was collected from the abdominal aorta. The tumor was harvested from the peritoneal cavity, and volume and cellularity were measured. Liver, heart and muscles were rapidly excised, weighed, frozen in liquid nitrogen, and stored at $-80^{\circ} \mathrm{C}$ until analysis.

Western blotting analysis. About $100 \mathrm{mg}$ of gastrocnemius muscle were homogenized in $80 \mathrm{mM}$ Tris- $\mathrm{HCl}$, pH 6.8 (containing $1 \mathrm{mM}$ DTT, $70 \mathrm{mM}$ SDS, and $1 \mathrm{mM}$ glycerol), kept on ice for $30 \mathrm{~min}$, centrifuged at $15000 \mathrm{x} \mathrm{g}$ for $10 \mathrm{~min}$ at $4^{\circ} \mathrm{C}$, and the supernatant collected. Protein concentration was assayed by the method of Lowry using BSA as working standard. Equal amounts of protein $(30 \mu \mathrm{g})$ were heatdenaturated in sample-loading buffer $(50 \mathrm{mM}$ Tris- $\mathrm{HCl}, \mathrm{pH}$ 6.8, $1 \mathrm{mM}$ DTT, 2\% SDS, $0.1 \%$ bromophenol blue, $10 \%$ glycerol), resolved on an SDS-PAGE and transferred for $2 \mathrm{~h}$ to nitrocellulose membranes (Bio-Rad, Hercules, CA, USA). Protein transfer was checked by Ponceau S staining. The filters were then blocked with TBS containing $0.05 \%$ Tween and 5\% non-fat dry milk and incubated overnight with primary antibodies specific for phosphorylated (p)-mTOR, mTOR, p-eIF2 $\alpha$, eIF2 $\alpha$, p-4EBP, 4EBP, p-p70S6K, p70S6K (Cell Signaling Technology, Danvers, MA, USA). All the primary antibodies were diluted 1:1000 in TBS containing $0.05 \%$ Tween and 5\% BSA. Goat anti-rabbit peroxidaseconjugated IgG (Bio-Rad, Hercules, CA, USA) was used as secondary antibodies. The filters were then stripped by incubation in $62.5 \mathrm{mM}$ Tris- $\mathrm{HCl}, \mathrm{pH} 6.7$, containing $100 \mathrm{mM}$ 2-mercaptoethanol and $2 \% \mathrm{SDS}$ for $30 \mathrm{~min}$ at $50^{\circ} \mathrm{C}$, and reprobed with a mouse monoclonal antibody directed against $\alpha$-tubulin ( $\sim 50 \mathrm{kDa}$; Sigma, St. Louis, MO, USA) to normalize sample loading. The membrane-bound immune complexes were detected by an enhanced chemiluminescence system (Santa Cruz Biotechnology, USA) on a photonsensitive film (Hyperfilm ECL; GE Healthcare, Milan, Italy). Bands were then quantified by densitometry scanning of the films and elaborated using a specific software (TotalLab, NonLinear Dynamics, Newcastle upon Tyne, UK).

Data presentation. Results are expressed as means \pm SD. Significance of the differences has been evaluated using Student's t-test for unpaired data. $\mathrm{p}<0.05$ was considered statistically significant.

\section{Results}

Effect of $H M B$ administration on food intake. Cumulative food intake was calculated for days 0-16 and 17-24 in all the 4 groups of rats (Table I). Rats treated with HMB showed a reduction in cumulative food intake in period 0-16, which was mainly accounted for by reduced food intake during the first week (days 0-7). 
Table I. Food intake in control and tumor-bearing rats.

\begin{tabular}{lcc}
\hline & $\begin{array}{c}\text { Food intake } \\
\text { day } 17-24(\mathrm{~g})\end{array}$ & $\begin{array}{c}\text { Total food intake } \\
(\mathrm{g})\end{array}$ \\
\hline $\mathrm{C}$ & $174 \pm 13$ & $472 \pm 42$ \\
$(\mathrm{n}=13)$ & & \\
$\mathrm{C}+$ HMB & & $419 \pm 27^{\mathrm{a}}$ \\
$(\mathrm{n}=16)$ & $164 \pm 11^{\mathrm{b}}$ & \\
$\mathrm{TB}$ & & $417 \pm 28^{\mathrm{a}}$ \\
$(\mathrm{n}=12)$ & $134 \pm 12^{\mathrm{a}}$ & \\
$\mathrm{TB}+\mathrm{HMB}$ & & $381 \pm 39^{\mathrm{c}}$ \\
$(\mathrm{n}=15)$ & $122 \pm 18^{\mathrm{a}}$ & \\
\hline
\end{tabular}

${ }^{\mathrm{a}} \mathrm{p}<0.001$ vs $\mathrm{C} ;{ }^{\mathrm{b}} \mathrm{p}=0.046$ vs $\mathrm{C} ;{ }^{\mathrm{c}} \mathrm{p}=0.013$ vs TB.

This was accompanied by a significant reduction in body weight with respect to untreated animals at day 16 . The growth of the AH-130 ascites hepatoma (days 17-24, TB group) was accompanied by a significant reduction in food intake, as it was expected. However, HMB administration did not further decrease food intake during tumor growth (day 17-24, TB + HMB group).

When considering the whole study period (days 0-24), HMB induced a significant reduction in food intake in both controls and tumor bearing animals, with respect to untreated rats (Table I). Total food intake (days 0-24) was similar in TB rats and HMB-treated controls.

Effect of HMB administration on body, carcass and organ weight. As expected, the growth of the AH-130 ascites hepa- toma induced a significant carcass weight and muscle loss (Table II). Treatment with HMB significantly prevented carcass weight loss in tumor-bearing rats, as indicated by the weight difference between day 16 (body weight) and day 24 (carcass weight, not including ascites) $(\mathrm{p}=0.003$ vs $\mathrm{TB}$, Table II), despite the reduction in total (days 0-24) food intake. Control rats treated with HMB showed a slight but significant reduction of body weight.

Loss of GSN muscle was also significantly attenuated by HMB in TB rats (Table II). Interestingly, in normal rats HMB induced a significant increase in GSN muscle and heart weight with respect to untreated controls. No differences were noted in the weight of soleus muscle, liver and spleen in both treated and untreated rats (Table II).

Effect of HMB administration on tumor growth. A slight, but statistically significant reduction in tumor growth was observed in HMB-treated tumor-bearing rats (data not shown).

Effect of HMB administration on intramuscular molecular pathways. Phosphorylated (p) eIF2 $\alpha$ markedly decreased in TB-rats vs. controls (Fig. 1). Although considerable, however, this difference did not reach statistical significance, likely due to variability among animals in the control group. Feeding the HMB-enriched diet tended to decrease p-eIF $2 \alpha$ levels in control animals, while no changes could be observed in the TB group (Fig. 1). Among the other kinases analysed in the present study, mTOR and p70S6K showed a parallel trend, since they both tended to be hyperphosphorylated in TB-rats even if the trend did not reach or was at the limit of statistical significance (Figs. 2 and 3). HMB administration to normal rats proved effective in enhancing $\mathrm{mTOR}$ and $\mathrm{p} 70 \mathrm{~S} 6 \mathrm{~K}$ phosphorylation above control levels. Similarly, p-mTOR and pp70S6K were further increased, although not significantly in HMB-treated TB in comparison with untreated TB (Figs. 2 and 3). Finally, TB-rats tended to have higher levels of p-4E-

Table II. Body and tissue weight in treated and untreated rats.

\begin{tabular}{|c|c|c|c|c|c|c|c|c|}
\hline & $\begin{array}{l}\text { Body weight } \\
\text { day } 16(\mathrm{~g})\end{array}$ & $\begin{array}{c}\text { Carcass weight } \\
\text { day } 24(\mathrm{~g})\end{array}$ & $\Delta \mathrm{WT}^{\mathrm{i}}$ & $\begin{array}{c}\text { GSN } \\
(\% \mathrm{IBW})\end{array}$ & $\begin{array}{l}\text { Soleus } \\
(\% \text { IBW })\end{array}$ & $\begin{array}{l}\text { Heart } \\
(\% \mathrm{IBW})\end{array}$ & $\begin{array}{l}\text { Spleen } \\
(\% \text { IBW })\end{array}$ & $\begin{array}{c}\text { Liver } \\
(\% \mathrm{IBW})\end{array}$ \\
\hline $\begin{array}{l}C \\
(n=13)\end{array}$ & $205 \pm 15$ & $252 \pm 18$ & $49 \pm 5$ & $0.63 \pm 0.05$ & $0.04 \pm 0.01$ & $0.32 \pm 0.03$ & $0.32 \pm 0.04$ & $5.8 \pm 0.5$ \\
\hline $\begin{array}{l}C+H M B \\
(n=16)\end{array}$ & $186 \pm 16^{\mathrm{a}}$ & $237 \pm 16^{c}$ & $51 \pm 5$ & $0.68 \pm 0.03^{\mathrm{f}}$ & $0.04 \pm 0.01$ & $0.36 \pm 0.03^{\mathrm{d}}$ & $0.32 \pm 0.04$ & $5.8 \pm 0.5$ \\
\hline $\begin{array}{l}\text { TB } \\
(n=12)\end{array}$ & $207 \pm 10$ & $205 \pm 12^{d}$ & $-3 \pm 7^{d}$ & $0.54 \pm 0.03^{\mathrm{d}}$ & $0.04 \pm 0.01$ & $0.30 \pm 0.02$ & $0.32 \pm 0.03$ & $5.4 \pm 0.3$ \\
\hline $\begin{array}{l}\mathrm{TB}+\mathrm{HMB} \\
(\mathrm{n}=15)\end{array}$ & $193 \pm 22^{b}$ & $207 \pm 24$ & $14 \pm 16^{e}$ & $0.57 \pm 0.04^{\mathrm{f}, \mathrm{g}, \mathrm{h}}$ & $0.04 \pm 0.01$ & $0.31 \pm 0.04$ & $0.33 \pm 0.05$ & $5.2 \pm 0.6$ \\
\hline
\end{tabular}

For TB and TB + HMB rats, weight at day 24 is carcass weight (not including ascites). IBW\%: percentage of initial body weight. ${ }^{\mathrm{a}} \mathrm{p}=0.005$ vs $C ;{ }^{b} p=0.045$ vs TB; ${ }^{c} p=0.021$ vs $C ;{ }^{d} p<0.001$ vs $C ;{ }^{e} p=0.003$ vs TB; ${ }^{\mathrm{f}} \mathrm{p}=0.002$ vs $\mathrm{C} ;{ }^{\mathrm{g}} \mathrm{p}=0.04$ vs TB; ${ }^{\mathrm{h}} \mathrm{p}<0.001$ vs $\mathrm{C}+\mathrm{HMB}$. ${ }^{\mathrm{i}} \Delta \mathrm{WT}$ : Body weight difference between day 16 (tumour inoculum) and day 24 (sacrifice). 
A

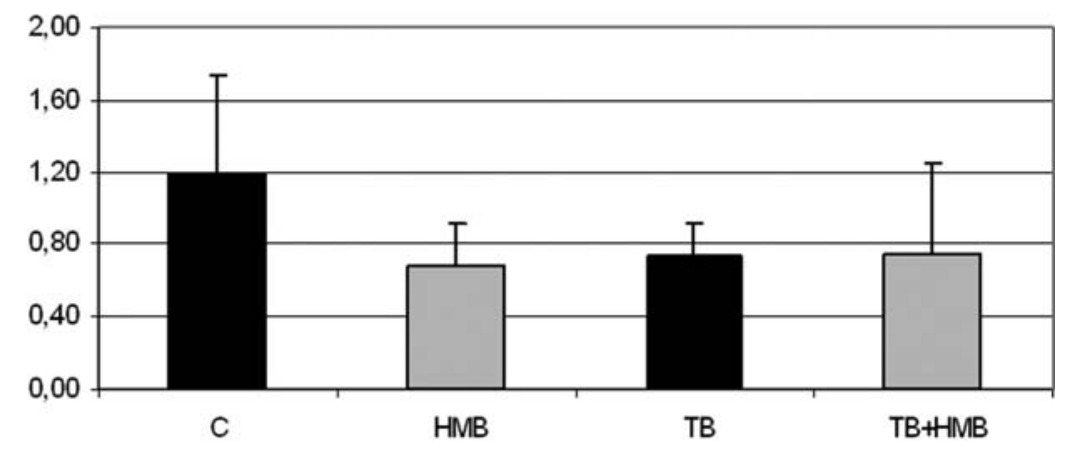

B

p-EIF2 a

EIF2 a

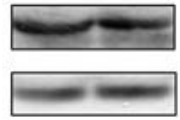

C

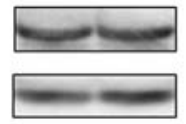

HMB

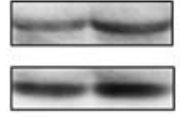

TB

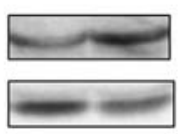

$\mathrm{TB}+\mathrm{HMB}$

Figure 1. (A) Densitometric analysis of Western blots for phosphorylated eIF2 $\alpha$ in gastrocnemius muscle in C ( $n=13)$, HMB $(n=16), T B(n=12)$ and TB + HMB $(n=15)$ animals. Data (means \pm SD) represent the ratio between total and phosphorylated eIF2 $\alpha$; (B) Representative Western blot pattern of phosphorylated and total eIF2 $\alpha$.

A

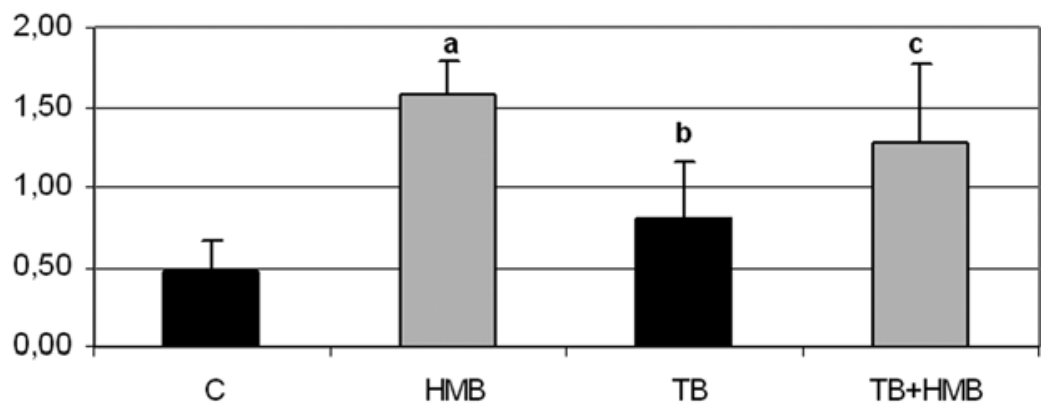

B

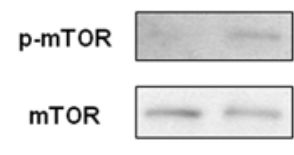

C

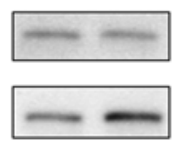

HMB

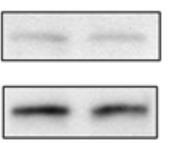

TB

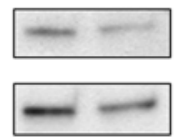

TB+HMB

Figure 2. (A) Densitometric analysis of Western blot for phosphorylated mTOR in gastrocnemius muscle $\left({ }^{\mathrm{a}} \mathrm{p}=0.0029\right.$ vs $\mathrm{C} ;{ }^{\mathrm{b}} \mathrm{p}=0.0216 \mathrm{vs} \mathrm{HMB} ;{ }^{\mathrm{c}} \mathrm{p}=0.0415$ vs C) in C $(n=13)$, HMB $(n=16)$, TB $(n=12)$ and TB + HMB $(n=15)$ animals. Data (means \pm SD) represent the ratio between total and phosphorylated mTOR; (B) Representative Western blot pattern of phosphorylated and total mTOR.

BP1 (Fig. 4) with respect to control values, that were not further modified by HMB administration. Similarly, HMB did not exert any effect on p-4E-BP1 levels in the controls (Fig. 4).

\section{Discussion}

B-hydroxy- $\beta$-methylbutyrate has been long proposed as an anabolic agent and has been widely employed in sports medicine to improve lean body mass and muscle strength in subjects undergoing resistance training exercise $(12,26)$ and in the elderly (28). Two main mechanisms have been proposed to explain the positive effects exerted by HMB, namely a down-regulation of muscle protein degradation and the attenuation of muscle damage likely achieved by stabilization of the sarcolemma $(12,13)$. The latter has been defined as the cholesterol synthesis hypothesis. Most of the intracellular HMB is converted into hydroxy-methyl-glutaryl-coenzyme-A 
A

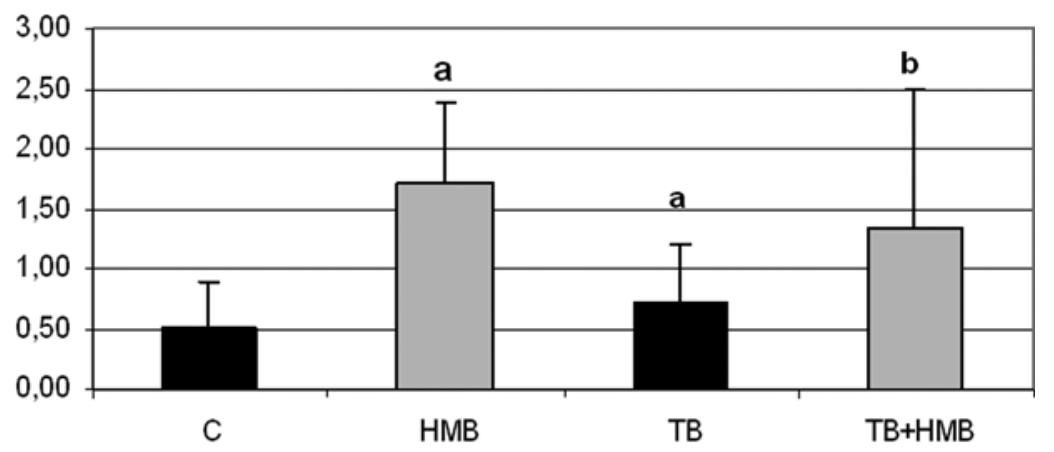

p-P70

B

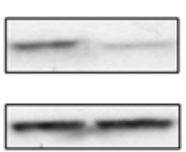

C

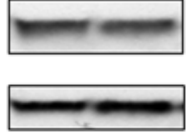

HMB

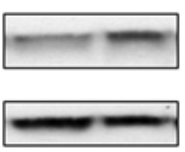

TB

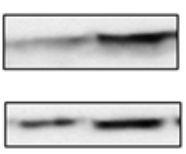

TB+HMB

Figure 3. (A) Densitometric analysis of Western blot for phosphorylated $\mathrm{p} 70 \mathrm{~S} 6 \mathrm{~K}$ in gastrocnemius muscle ( ${ }^{\mathrm{a}} \mathrm{p}=0.05$ vs $\mathrm{C}$; ${ }^{\mathrm{b}} \mathrm{p}=0.06 \mathrm{vs} \mathrm{HMB}$ ) in $\mathrm{C}$ ( $\mathrm{n}=13$ ), HMB $(n=16)$, TB $(n=12)$ and TB + HMB $(n=15)$ animals. Data (means \pm SD) represent the ratio between total and phosphorylated P70S6K; (B) Representative Western blot pattern of phosphorylated and total P70S6K.

A

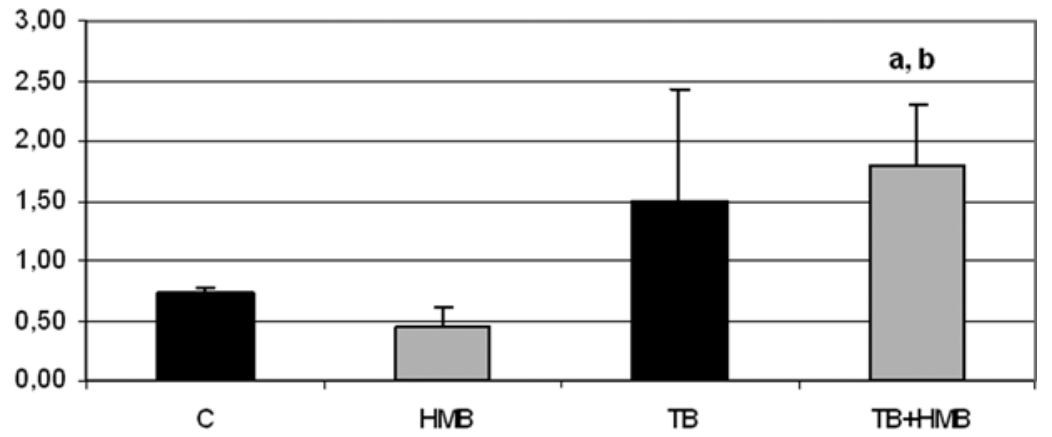

p-4EBP1

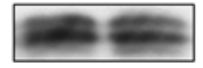

4EBP1

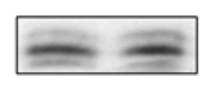

C
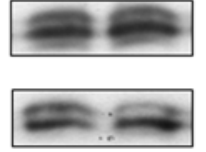

HMB

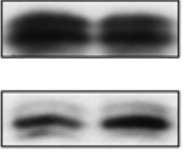

TB

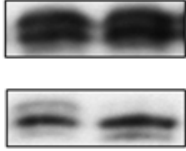

$\mathrm{TB}+\mathrm{HMB}$

Figure 4. (A) Densitometric analysis of Western blot for phosphorylated 4-EB-P1 in gastrocnemius muscle ( ${ }^{\mathrm{a}} \mathrm{p}=0.02$ vs $\mathrm{C}$; ${ }^{\mathrm{b}} \mathrm{p}=0.008$ vs $\left.\mathrm{HMB}\right)$ in $\mathrm{C}$ ( $\mathrm{n}=13$ ), HMB $(n=16)$, TB $(n=12)$ and TB + HMB $(n=15)$ animals. Data (means \pm SD) represent the ratio between total and phosphorylated 4-EB-P1; $(B)$ Representative Western blot pattern of phosphorylated and total 4-EB-P1.

(HMG-CoA), one of the substrates in cholesterol biosynthesis. In this regard, increased HMB availability within the muscle would enhance cholesterol production, allowing sarcolemma repair and stabilization $(12,29,30)$. Not only, the increased synthesis of mevalonic acid, the cholesterol precursor deriving from $\mathrm{HMG}-\mathrm{CoA}$ reductase activity, may result in enhanced levels of coenzyme Q10 (31), the lack of which has been proposed to play a role in the pathogenesis of muscle atrophy $(32,33)$. On the contrary, a single report suggests that HMB might prevent muscle wasting by decreasing the rates of protein catabolism through downregulation of the ATP-dependent ubiquitin-proteasome pathway (15).

More recently, however, the hypothesis that HMB might directly stimulate muscle protein anabolism has been proposed. In this respect, a crucial step in the anabolic response is phosphorylation and activation of the kinase mammalian target of rapamycin (mTOR) (34) (Fig. 5), which in turn 


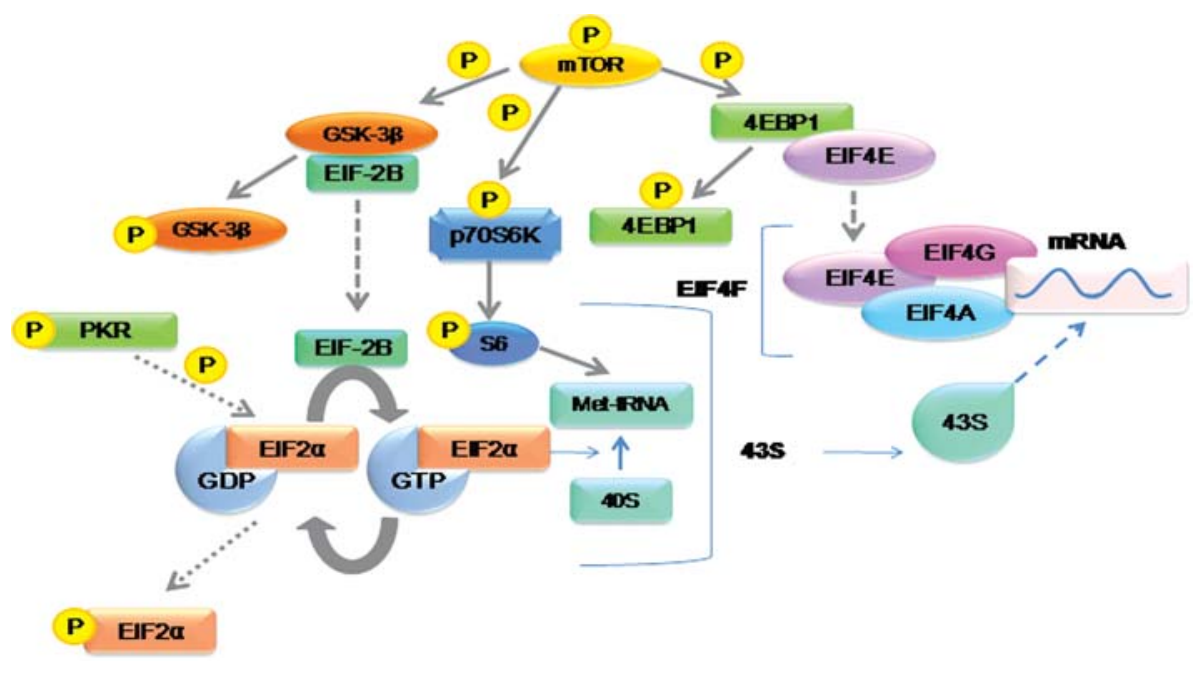

Figure 5. Schematic representation of mTOR signaling.

activates p70S6 kinase (p70S6K) and inhibits 4E-BP1 (also known as PHAS-1), positive and negative regulators of translation initiation, respectively. The latter competes with eIF4G for binding to eIF4E: when 4E-BP1 is hypophosphorylated, it tightly binds eIF4E to form the translationally inactive eIF4E/4E-BP1 complex. By contrast, when 4E-BP1 is phosphorylated, eIF4E is released and presumably available for binding to eIF4G (35). eIF4E, together with eIF4G and EIF4A, forms the eIF4F complex, that is crucially involved in mRNA translation (34). Phosphorylation of 4E-BP1 induced by growth factors such as insulin and IGF-I has been shown to depend on the Akt/PI3K/mTOR pathway (35), whereas an Akt-unrelated, mTOR-dependent activation has been proposed to results from increased intracellular amino acid availability (35). In a parallel pathway, the eIF2 complex formed by eIF $2 \alpha, \beta$ and $\gamma$, binds the Met-tRNA to the 40S ribosomal subunit to form the $43 \mathrm{~S}$ initiation complex. During this process the eIF2-associated GTP is hydrolysed to GDP. Recycling of eIF2-GDP to eIF2-GTP requires the guanine nucleotide exchange factor eIF2B (36), whose activity is induced via phosphorylation by the glycogen-synthase kinase (GSK)-3ß (37). Several kinases can phosphorylate eIF2 $\alpha$, leading to inhibition of eIF2B, and to consequent reduction of eIF2-GTP levels, resulting in decreased translation (38).

In the present study the growth of the $\mathrm{AH}-130$ ascites hepatoma induced significant loss of carcass weight and GSN muscle mass, which was comparable with our previous observations in the same model $(6,9)$. The data obtained show that early HMB administration may attenuate loss of muscle and body weight characteristic of cancer cachexia. Indeed, in the AH-130 tumor-bearing rats, HMB treatment not only prevented the anticipated body weight loss (39), but was capable of inducing an increment in body weight following tumor inoculum. Moreover, the loss of GSN muscle was attenuated by HMB with respect to untreated tumor-bearing rats. Attenuation of body weight and muscle loss occurred despite reduction in total food intake, suggesting that the anabolic effect of HMB may overcome the possible effects of reduced nutrient availability. Conversely, in control rats, although HMB treatment induced a reduction in food intake associated with a reduction in body weight, a significant increase in GSN muscle mass was observed. Despite total (days 0-24) food intake was similar in C + HMB and TB rats, carcass weight at day 24 was markedly and significantly different between these groups $(237 \pm 16.48$ vs $204.58 \pm 11.94 \mathrm{~g}$, in $\mathrm{TB}$ and $\mathrm{C}+\mathrm{HMB}$, respectively, $\mathrm{p}<0.001$ ), confirming that the presence of the tumor per se, rather than reduced food intake, has a major role in the pathogenesis of weight loss in cancer cachexia.

Our results are in agreement with previous clinical and experimental data suggesting that HMB may exert a positive role in counteracting cancer-related wasting. May et al (19) showed that the daily administration of $3 \mathrm{~g} \mathrm{HMB}$, in combination with arginine and glutamine, increases body weight and lean body mass in advanced, cachectic cancer patients. Smith and co-workers found that, in mice bearing the MAC-16 tumor, doses of HMB $>0.125 \mathrm{~g} / \mathrm{kg}$ significantly attenuate weight loss and increase soleus muscle mass. These findings were accompanied by reduced expression of proteasome subunits, decreased proteasome chymotrypsin-like activity, attenuated protein degradation and increased protein synthesis rates within muscle tissue (15). Although we did not measure protein synthesis, the present study suggests that, at least in the AH-130 model of cancer cachexia, HMB administration may prevent muscle wasting by modulating the activity of molecules crucially involved in the anabolic response. Indeed, the levels of phosphorylated mTOR and p70S6K, already enhanced in the AH-130 hosts, further increased after HMB treatment in both controls and tumor bearers, while those of p-eIF $2 \alpha$ further decreased in the latter. Similar effects of HMB administration were observed by Eley and colleagues in mice bearing the MAC-16 tumor, although, differently from the AH-130 bearers, the state of activation of both mTOR and p70S6K was reduced in the untreated MAC- 16 hosts (16). The authors showed that $0.25 \mathrm{~g} / \mathrm{kg}$ HMB may reduce the level of phosphorylation of downstream molecules involved in anabolic signaling, namely PKR and eIF2 $\alpha$. In the same study, addition of $\mathrm{HMB}$ to $\mathrm{C} 2 \mathrm{C} 12$ myotube cultures was shown to increase the basal phosphorylation levels of mTOR, p70S6K and 4E-BP1. Moreover, HMB was also able 
to counteract the reduction of p-mTOR and p-p70S6K and to increase the phosphorylation of 4E-BP1 in PIF-treated $\mathrm{C} 2 \mathrm{C} 12$ cultures.

Unlike in this in vitro observation, in the present investigation the phosphorylation of 4E-BP1 not only was greater in tumor-bearing than in control rats, but it was also unaffected by HMB in both control and tumor-bearing rats. These differences, however, may well be due to the different (in vitro vs in vivo) experimental settings. In our study, HMB administration in controls rats did not influence 4E-BP1 phosphorylation in spite of the elevated level of p-mTOR: possible explanations for this finding might be that phosphorylation of 4-EB-P1 is not solely dependent of mTOR phosphorylation and/or it might be also influenced by a specific phosphatase activity.

The results of the present study demonstrate that administration of HMB improves cancer-related muscle wasting and body weight loss. It is known that the AH-130 tumor causes muscle atrophy mainly by enhancing muscle protein catabolism, while the rates of synthesis remain comparable to controls (40). Despite this, as shown in the present study the skeletal muscle of the AH-130 hosts shows a pro-synthetic molecular pattern, since the levels of p-mTOR, p-p70S6K and p-4E-BP1 tend to be higher than in controls, while those of p-eIF $2 \alpha$ tend to be lower. These observations suggest that in the AH-130-bearing rats the skeletal muscle, although atrophying, retains the ability to activate a compensatory anabolic response, that however does not result in synthesis rates above those of controls. HMB administration, while ineffective in modifying the levels of both p-eIF $2 \alpha$ and p-4EBP1, further increases mTOR and p70S6K phosphorylation. HMB could therefore boost protein synthesis by increasing the phosphorylation of the ribosomal protein S6, that works as an adaptor between the $40 \mathrm{~S}$ and $60 \mathrm{~S}$ ribosomal subunits (41). Future studies will be aimed at verifying this point, by concomitantly measuring protein synthetic rate in muscle.

A major concern in nutritional supplementation in cancer is the theoretical risk of feeding the tumor, particularly when molecules with claimed anabolic actions are used. However, the data obtained in the present investigation, in agreement with what previously shown by others (15) would suggest that HMB reduces tumor growth. The mechanisms underlying this positive effect are unclear, and deserve further investigation. It could be argued that the protective effects exerted on muscle and body weight by HMB supplementation in tumor-bearing rats might be indeed secondary to decreased tumor growth. However, this concern is weakened by the clearcut effects of $\mathrm{HMB}$ on muscle weight and signaling molecules achieved in controls, which strengthens the view that the anti-cachectic effects are mainly mediated by a direct HMB effect on muscle metabolism.

In conclusion, the results obtained in the present study suggest that HMB is associated with attenuation of muscle loss in an experimental model of cancer cachexia. Preservation of muscle mass is associated to increased phosphorylation of key anabolic molecules, suggesting that HMB action is mediated by improved protein anabolism in muscle. No such similar concomitant phenotypical benefits and molecular changes were observed in intervention studies in this model. The administration of HMB alone or in combination with other drugs and/or nutrients might represent a safe and effective way to prevent $(42,43)$ the loss of lean body mass in cancer cachexia. Finally, the hypothesis that HMB administration may attenuate muscle mass and body weight loss through a reduction of tumor growth deserves further investigation.

\section{References}

1. Muscaritoli M, Bossola M, Aversa Z, Bellantone R and Rossi Fanelli F: Prevention and treatment of cancer cachexia: new insight into an old problem. Eur J Cancer 42: 31-41, 2006.

2. MacDonald N, Easson AM and Mazurak VC, et al: Understanding and managing cancer cachexia. J Am Coll Surg 197: $143-161,2003$

3. Costelli P and Baccino FM: Cancer cachexia: from experimental models to cancer patients. Curr Opin Clin Nutr Metab Care 60: 177-181, 2000.

4. Ciechanover A: The ubiquitin-proteasome proteolytic pathway. Cell 79: 13-21, 1994.

5. Kadovaki M and Kanazawa T: Amino acids as regulators of proteolysis. J Nutr 133 (Suppl. 6): S2052-S2056, 2003.

6. Costelli P, Bossola M and Muscaritoli M, et al: Anti-cytokine treatment prevents the increase in the activity of ATP-ubiquitin and $\mathrm{Ca}^{2+}$-dependent proteolytic systems in the muscle of tumour-bearing rats. Cytokine 19: 1-5, 2002.

7. Du J, Wang X, Miereles C, Bailey JL, Debigare R and Zheng B: Activation of caspase- 3 is an initial step triggering accelerated muscle proteolysis in catabolic conditions. J Clin Invest 113: 115-123, 2004.

8. Costelli P, Muscaritoli M, Bossola M, Penna F, Reffo P, Bonetto A, Busquets S, Bonelli G, Lopez-Soriano FJ, Doglietto GB, Argilés JM, Baccino FM and Rossi Fanelli F: IGF-1 is downregulated in experimental cancer cachexia. Am J Physiol Regul Integr Comp Physiol 291: R674-R683, 2006.

9. Costelli P, Muscaritoli M, Bonetto A, Penna F, Reffo P, Bossola M, Bonelli G, Doglietto GB, Baccino FM and Rossi Fanelli F: Muscle myostatin signalling is enhanced in experimental cancer cachexia. Eur J Clin Invest 38: 531-538, 2008.

10. Nissen SL and Abumrad NN: Nutritional role of the leucine metabolite $\beta$-hydroxy- $\beta$-methylbutyrate (HMB). J Nutr Biochem 8: 300-311, 1997.

11. Frexes-Steed M, Lacy DB, Collins J and Bumrad NN: Role of leucine and other amino acids in regulating protein metabolism in vivo. Am J physiol 262: E925-E935, 1992.

12. Nissen S, Sharp R and May M, et al: Effect of leucine metabolite $\beta$-hydroxy- $\beta$-methylbutyrate on muscle metabolism during resistence exercise training. J Appl Physiol 81: 2095-2104, 1996.

13. Smith HJ, Wyke SM and Tisdale MJ: Mechanism of the attenuation of proteolysis-inducing factor stimulated protein degradation in muscle by $\beta$-hydroxy- $\beta$-methylbutyrate. Cancer Res 64: 8731-8735, 2004.

14. Paddon-Jones D, Sheffield-Moore M and Urban RJ, et al: Essential aminoacid and carbohydrate supplementation ameliorates muscle protein loss in humans during 28 days bedrest. J Clin Endocrinol Metab 89: 4531-4538, 2004.

15. Smith HJ, Mukerji P and Tisdale MJ: Attenuation of proteasomeinduced proteolysis in skeletal muscle by $\beta$-hydroxy- $\beta$ methylbutyrate in cancer-induced muscle loss. Cancer Res 65: 277-283, 2005.

16. Eley HL, Russel ST, Baxter JH, Mukerji P and Tisdale MJ: Signaling pathways initiated by $ß$-hydroxy-ß-methylbutyrate to attenuate the depression of protein synthesis in skeletal muscle in response to cachectic stimuli. Am J Physiol Metab 293: E923-E931, 2007.

17. Panton LB, Rathmacher JA, Baier S and Nissen S. Nutritional supplementation of the leucine metabolite $\beta$-hydroxy- $\beta$ methylbutyrate (HMB) during resistance training. Nutrition 16 : 734-739, 2000.

18. Van Someren KA, Edwards AJ and Howatson G: Supplementation with beta-hydroxy-beta-methylbutyrate (HMB) and alphaketoisocaproic acid (KIC) reduces signs and symptoms of exercise-induced muscle damage in man. Int J Sport Nutr Exerc Metab 15: 413-424, 2005.

19. May PE, Barber A, D'Olimpio JT, Hourihane A, Naji N and Abumrad MD: Reversal of cancer-related wasting using oral supplementation with a combination of $\beta$-hydroxy- $\beta$-methylbutyrate (HMB), arginine and glutamine. Am J Surg 183: 471-479, 2002. 
20. Berk L, James J, Scwartz A, et al: A randomized, double-blind, placebo-controlled trial of a $\beta$-hydroxyl- $\beta$-methyl butyrate, glutamine, and arginine mixture for the treatment of cancer cachexia (ROTG 0122). Support Care Cancer 16: 1179-1188 2008.

21. Clark RH, Feleke G and Din M, et al: Nutritional treatment for acquired immunodeficiency virus-associated wasting using beta-hydroxy beta-methylbutyrate, glutamine, and arginine: a randomized, double-blind, placebo-controlled study. JPEN Parenter Enter Nutr 24: 133-139, 2000.

22. Rathmacher JA, Nissen S and Panton L, et al: Supplementation with a combination of beta-hydroxy-beta-methylbutyrate (HMB), arginine, and glutamine is safe and could improve haematological parameters. JPEN J Parenter Enter Nutr 28: 65-75, 2004.

23. Marcora S, Lemmey A and Maddison P: Dietary treatment of rheumatoid cachexia with beta-hydroxy-beta-methylbutyrate, glutamine and arginine: a randomised controlled trial. Clin Nutr 24: 442-454, 2005.

24. Kuhls DA, Rathmacher JA and Musngi MD, et al: $\beta$-hydroxy-ßmethylbutyrate supplementation in critically ill trauma patients. J Trauma 62: 125-132, 2007.

25. Hsieh LC, Chien SL, Huang MS, Tseng HF and Chang CK: Anti-inflammatory and anticatabolic effects of short-term betahydroxy-beta-methylbutyrate supplementation on chronic obstructive pulmonary disease patients in intensive care unit. Asia Pac J Clin Nutr 15: 544-550, 2006.

26. Wilson GJ, Wilson JM and Manninem AH: Effects of betahydroxy-beta-methylbutyrate (HMB) on exercise performance and body composition across varying levels of age, sex and training experience: a review. Nutr Metab (Lond) 3: 1-17, 2008.

27. Gallagher PM, Carrithers JA, Godard MP, Schulze KE and Trappe SW: Beta-hydroxy-beta-methylbutyrate ingestion, part II: effect on hematology, hepatic and renal function. Med Sci Sports Exerc 32: 2116-2119, 2000.

28. Flakoll P, Sharp R, Baier S, Levenhagen D, Carr C and Nissen S: Effect of $\beta$-hydroxy- $\beta$-methylbutyrate, arginine, and lysine supplementation on strenght, functionality, body composition, and protein metabolism in elderly women. Nutrition 20: 445451, 2004

29. Nissen S, Sharp RL, Panton L, Vukovich M, Trappe S and Fuller JC Jr: ß-hydroxy-ß-methylbutyrate (HMB) supplementation in humans is safe and may decrease cardiovascuylar risk factors. J Nutr 130: 1937-1945, 2000.

30. Bachhawat BK, Robinson WG and Coon MJ: Enzymatic carboxylation of beta-hydroxyisovaleryl coenzyme A. J Biol Chem 219: 539-550, 1956.

31. Evans M and Rees A: Effects of HMG-CoA reductase inhibitors on skeletal muscle: are all statins the same? Drug Saf 25: 649-663, 2002 .
32. Daneryd P, Aberg F, Dallner G, Ernster L, Scherstén T and Soussi B: Coenzymes Q9 and Q10 in skeletal and cardiac muscle in tumour-bearing exercising rats. Eur J Cancer 31A: 760-765, 1995.

33. Folkers K and Simonsen R: Two successful double-blind trials with coenzyme Q10 (vitamin Q10) on muscular dystrophies and neurogenic atrophies. Biochim Biophys Acta 1271: 281-286, 1995.

34. Gingras A-C, Raught B and Sonenberg N: eIF4 initiation factors: effectors of mRNA recruitment to ribosomes and regulators of translation. Ann Rev Biochem 68: 913-963, 1999.

35. Shen W, Boyle DW, Wisniowski P, Bade A and Liechty A: Insulin and IGF-I stimulate the formation of the eukariotik initiation factor $4 \mathrm{~F}$ complex and protein synthesis in $\mathrm{C} 2 \mathrm{C} 12$ myotubes independent of availability of external amino acids. J Endocrinol 185: 275-289, 2005.

36. Price $\mathrm{N}$ and Proud $\mathrm{C}$ : The guanine nucleotide-exchange factor, eIF-2B. Biochimie 76: 748-760, 1994.

37. Jefferson LS, Fabian JR and Kiball SR: Glycogen synthase kinase-3 in the predominant insulin-regulated eukaryotic initiation factor $2 \mathrm{~B}$ kinase in skeletal muscle. Int J Biochem Cell Biol 31: 191-200, 1999.

38. Rowlands AG, Panniers R and Henshaw EC: The catalytic mechanism of guanine nucleotide exchange factor action and competitive inhibition by phosphorylated eukaryotic initiation factor 2. J Biol chem 263: 5526-5533, 1998.

39. Tessitore L, Costelli P, Bonetti G and Baccino FM: Cancer cachexia, malnutrition, and tissue protein turnover in experimental animals. Arch Biochem Biophys 306: 52-58, 1993.

40. Tessitore L, Bonelli G, Cecchini G, Amenta JS and Baccino FM: Regulation of protein turnover versus growth state: ascites hepatoma as a model for studies both in the animal and in vitro. Arch Biochem Biophys 255: 372-384, 1987.

41. Chaberge S, Cassarino E and Mangiarotti G: The phosphorylation of protein S6 modulates the interaction of the $40 \mathrm{~S}$ ribosomal subunit with the 5'-untranslated region of a dictyostelium prespore-specific mRNA and controls its stability. J Biol Chem 273: 27070-27075, 1998.

42. Muscaritoli M, Costelli P, Aversa Z, Bonetto A, Baccino FM and Rossi Fanelli F: New strategies to overcome cancer cachexia: from molecular mechanisms to the 'Parallel Pathway'. Asia Pac J Clin Nutr 17 (Suppl. 1): S387-S390, 2008.

43. Muscaritoli M, Molfino A, Gioia G, Laviano A and Rossi Fanelli F: The 'parallel pathway': a novel nutritional and metabolic approach to cancer patients. Intern Emerg Med, Jul 2, [Epub ahead of print], 2010. 